\title{
To study the correlation between endometrial thickness on transvaginal sonography and endometrial histopathology in women with postmenopausal bleeding
}

\author{
Leena Chaudhari, Meena N. Satia*
}

Department of Obstetrics and Gynaecology, Seth G.S Medical College and K.E.M hospital, Mumbai, Maharashtra, India

Received: 20 April 2016

Accepted: 25 April 2016

*Correspondence:

Dr. Meena N. Satia,

E-mail: meenasatia@kem.edu

Copyright: () the author(s), publisher and licensee Medip Academy. This is an open-access article distributed under the terms of the Creative Commons Attribution Non-Commercial License, which permits unrestricted non-commercial use, distribution, and reproduction in any medium, provided the original work is properly cited.

\begin{abstract}
Background: Endometrial carcinoma is the most common malignancy of the female genital tract, ranking second to carcinoma cervix. It occurs primarily in postmenopausal women. Majority of women with endometrial cancer present with postmenopausal bleeding $(90 \%)$ but in only about $15 \%$ of women is endometrial cancer the cause of postmenopausal bleeding. The objective of current study is to study the correlation between endometrial thickness on transvaginal sonography and endometrial histopathology in women with postmenopausal bleeding and whether endometrial thickness $>4 \mathrm{~mm}$ is more suggestive of hyperplasia or carcinoma.

Methods: The cases were selected from amongst the patients attending gynaecology OPD, who had history of postmenopausal bleeding or spotting per vaginum and were subjected to TVS followed by endometrial sampling by brush cytology Diagnostic Hysteroscopy was done which was followed by fractional curettage. The material obtained by sampling studied for endometrial histopathology.

Results: Atrophic endometrium's followed by proliferative endometrium was the most common histological findings and $9 \%$ patients had adenocarcinoma. Mean endometrial thickness on TVS was $5.97 \mathrm{~mm}$ for atrophic histology and $11.95 \mathrm{~mm}$ for carcinoma.

Conclusions: Postmenopausal bleeding, should always be taken seriously, no matter how minimal or nonpersistent it is, because though majority of causes underlying postmenopausal bleeding are benign, endometrial carcinoma may be seen in around $10 \%$ cases. So, patients with PMB must undergo thorough evaluation by endometrial sampling which cannot be replaced by transvaginal sonography which though has more sensitivity to detect endometrial thickening, at the same time, has low specificity for detection of malignancy.
\end{abstract}

Keywords: Postmenopausal bleeding, Transvaginal sonography, Endometrial histopathology

\section{INTRODUCTION}

Postmenopausal bleeding (PMB) accounts for five per cent of office gynaecology presentations. ${ }^{1}$ Its definition is self-explanatory, as any bleeding from the genital tract occurring in the postmenopausal period, arising after 12 months of amenorrhoea in a woman of menopausal age. ${ }^{2}$ Generally, four to 11 per cent of postmenopausal women will experience bleeding. ${ }^{1}$ The chance of this occurring reduces as time since menopause increases. ${ }^{1}$
Aetiology while the most common cause for PMB is atrophy, the diagnostic algorithm for PMB is designed to detect cancer, particularly endometrial cancer. ${ }^{1}$

Endometrial carcinoma is the most common malignancy of the female genital tract, ranking second to carcinoma cervix. Overall, $2 \%$ to $3 \%$ women develop endometrial carcinoma during their lifetime. ${ }^{3}$ It occurs primarily in postmenopausal women and is increasingly virulent with advancing age. Any factor that increases exposure to unopposed estrogen increases the risk for endometrial 
cancer $^{2}$. Majority of women with endometrial cancer present with postmenopausal bleeding $(90 \%)$ but in only about $15 \%$ of women is endometrial cancer the cause of postmenopausal bleeding.

\section{Table 1: Origin of PMB incidence.}

\begin{tabular}{|ll|}
\hline Atrophy & $60-80 \%$ \\
\hline Exogenous estrogens & $15-25 \%$ \\
\hline Polyps & $2-12 \%$ \\
\hline Endometrial hyperplasia & $10 \%$ \\
\hline Endometrial cancer & $10 \%$ \\
\hline Cervical cancer & Less than $1 \%$ \\
\hline
\end{tabular}

Fortunately, most of the patients with endometrial cancer present with abnormal peri or postmenopausal bleeding early in the development of disease, when the tumour is still confined to the uterus.

Application of an appropriate and accurate diagnostic test in this situation usually results in early diagnosis, timely treatment and a high cure rate bleeding from the genital tract occurring after the menopause is much more sinister than pre-menopausal bleeding. ${ }^{6}$

In the absence of hormone therapy; any bleeding after menopause, should prompt evaluation with endometrial sampling. ${ }^{7}$ Even without amenorrhea or irregular bleeding, if a woman over the age of 52 years continues to menstruate, she needs investigations to rule out endometrial hyperplasia and malignancy of the genital tract.

The dictum is postmenopausal bleeding indicates malignancy until proved otherwise The challenge for the gynaecologist is in determining which diagnostic approach to consider for a patient with postmenopausal bleeding. The traditional gold standard is to perform dilatation and curettage but due to its invasiveness and need for anaesthesia; it has been replaced by an office endometrial biopsy.

Early symptoms reflecting early disease had been the explanation for the good prognosis of carcinoma endometrium Transvaginal sonography (TVS) is another modality of investigation which is non-invasive and has similar sensitivity as endometrial biopsy. ${ }^{6}$ Endometrial thickness $<5 \mathrm{~mm}$ on TVS can exclude endometrial disease in majority of postmenopausal women with bleeding per vaginum. $^{7}$

The Aim of this study was to evaluate the women with postmenopausal bleeding by measuring the endometrial thickness by Transvaginal sonography followed by endometrial sampling by fractional curettage and correlate the endometrial thickness with histological findings and to assess whether endometrial thickness of $>4 \mathrm{~mm}$ on TVS is more suggestive of malignancy.

\section{METHODS}

A prospective diagnostic study was conducted in the Department of Obstetrics and gynaecology at Seth G.S. Medical College and K.E.M. Hospital, Parel, Mumbai, from December 2011 to October 2012. The study protocol received approval by Institutional research advisory committee and ethics committee. All women with postmenopausal bleeding attending outpatient department (OPD) of Obstetrics and Gynecology, at Seth G.S. Medical College and K.E.M. Hospital, Parel, Mumbai, were offered voluntary participation in the study after written informed consent. Every participant was free to withdraw from the study at any time of study duration for any reason. One hundred patients with PMB were recruited and subjected to detailed questionnaire about duration since menopause, duration of postmenopausal bleeding, significant medical and surgical history in past and history of hormonal contraception used and any past gynaecological examination and evaluation undergone.

They were then subjected to trans-vaginal sonography followed by endometrial brush cytology; Diagnostic Hysteroscopy along with fractional curettage was done after thorough clinical examination and work- up. Women with age <45 years, women on anticoagulant therapy or on hormone replacement therapy and with clinically diagnosed cervical lesions were excluded from the study. After that, all of them were subjected to Diagnostic hysteroscopy followed by endometrial sampling by fractional curettage. This involves obtaining samples for histopathology under anaesthesia from cervical canal and all the four walls of the uterine cavity including isthmus which helps to improve accuracy of the diagnosis.

The material obtained by sampling studied for endometrial histopathology which was reported by a pathologist. It showed a spectrum of endometrial histopathology as follows (a) normal, atrophic, secretory or proliferative phase endometrium, (b) hyperplasia metaplasia dysplasia carcinoma of endometrium.

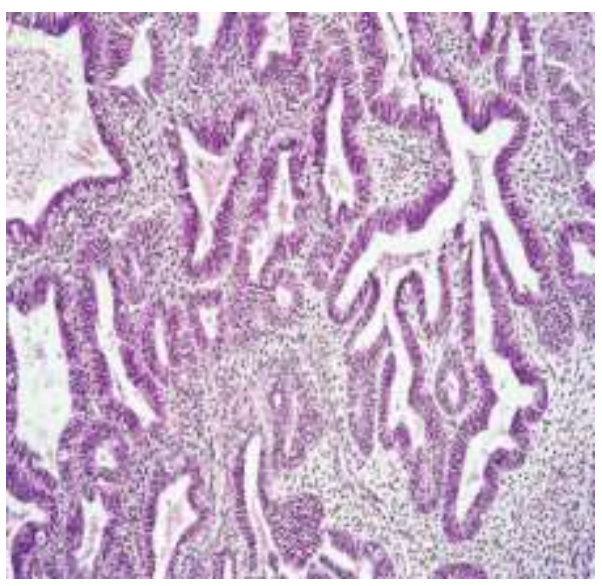

Figure 1: Endometrial hyperplasia. 

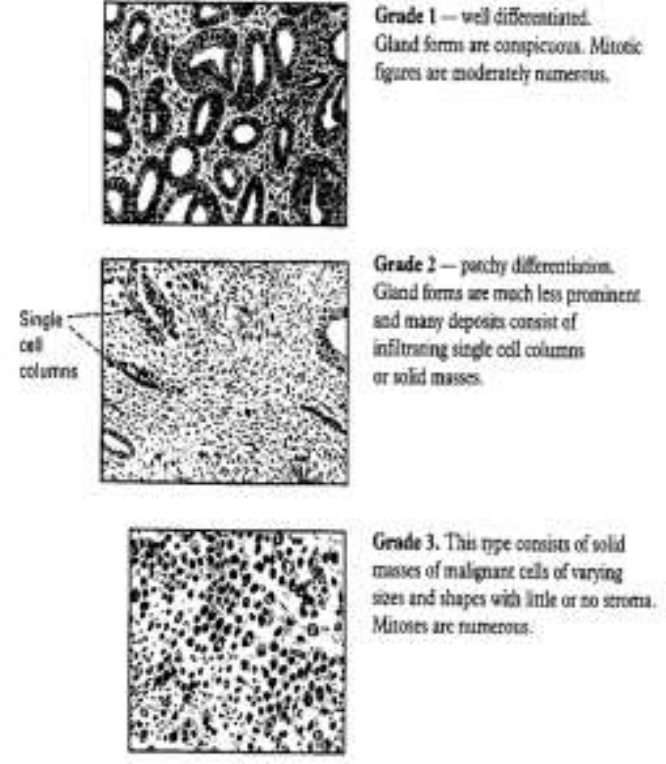

Figure 2: Carcinoma endometrium.

Treatment was given to the patient according to the histopathology report.

1. Normal/atrophic endometrium: symptomatic treatment.

2. Proliferative endometrium: dilatation and curettage.

3. Endometrial polyp: blind curettage/Hysteroscopic removal.

4. Hyperplasia; (a) Hyperplasia without atypiaMedroxyprogesterone acetate $10-20 \mathrm{mg} /$ day. (b) Hyperplasia with atypia- high dose progestin therapy either Medroxy progesterone acetate $200 \mathrm{mg} / \mathrm{d}$ or $160 \mathrm{mg} / \mathrm{d}$ for 9 months or Levonorgestrel intrauterine system. ${ }^{8}$

5. Metaplasia: symptomatic treatment with regular followup.

6. Dysplasia: cryotherapy/ laser ablation/ loop electrosurgical excision/ conisation.

7. Carcinoma: eithersurgery/ radiotherapy/ chemotherapy or combined therapy depending upon the stage of carcinoma.

The primary outcome measured was correlation between endometrial thickness and endometrial histopathology. Secondary outcome included was whether endometrial thickness $>4 \mathrm{~mm}$ is more suggestive of hyperplasia or carcinoma.

\section{RESULTS}

The parameters analyzed were as follows: most common age group affected by $\mathrm{PMB}$, most common age group in carcinoma cases, parity of patients and its association with carcinoma, symptoms of the patients, duration and no of episodes of bleeding, whether bleeding present at the time of examination, associated co-morbidities, family history of PMB, H/O past gynaecological event,
$\mathrm{H} / \mathrm{O}$ and different forms of contraceptive use, PAP smear and endometrial thickness on TVS, histopathological diagnosis, endometrial thickness in benign and malignant lesions.

After the analysis, the results obtained were as following-

1. Most of the women presenting with postmenopausal bleeding were in $5^{\text {th }}$ and $6^{\text {th }}$ decade of life and in II B stage of menopause.

2. Though incidence of postmenopausal bleeding is greater in immediate postmenopausal age group, the incidence of carcinoma is more in the age group $>50$ years and steadily increases thereafter.

3. Multiparity has shown an association with carcinoma with 8 out of 9 carcinomatous patients having parity $>3$.

4. Most common symptom among these patients was painless vaginal bleeding. Majority of them had this symptom for less than a month with 1 to 3 episodes of bleeding or spotting on average reflecting the early seeking of medical help for the problem.

5. PAP smear is inconclusive in predicting outcome in cases of postmenopausal bleeding but it surely helps to rule out carcinoma cervix as the underlying cause, however its efficacy in predicting carcinoma endometrium is only $65 \%$.

6. Out of 100,27 patients had associated comorbidities, most common being hypertension followed by diabetes.

7. 8 out of 9 patients who diagnosed with carcinoma uterus had associated hypertension or diabetes. Association was also seen between carcinoma and obesity. This supports the hypothesis of corpus cancer syndrome.

8. $79 \%$ cases of PMB had benign histological lesions such as normal or secretory or atrophic and proliferative endometrium. The most common cause of postmenopausal bleeding being atrophic endometrium. Mean ET was about $5.97 \mathrm{~mm}$ in atrophic endometrium and $11.95 \mathrm{~mm}$ in carcinomatous endometrium.

9. Most common histological type of endometrial carcinoma was endometroid type (adenocarcinoma). ${ }^{7}$

\section{DISCUSSION}

Menopause is defined as permanent cessation of menses. By convention, the diagnosis of menopause is not made until the individual has had 12 months of amenorrhoea. Postmenopausal bleeding is defined as any bleeding through genital tract after 12 months of cessation of menstruation. There are different causes of postmenopausal bleeding. Unless proved otherwise, all cases of postmenopausal bleeding has to be considered having underlying malignancy.

Although most common cause found on investigations is benign, but as about $10 \%$ cases of postmenopausal bleeding has endometrial carcinoma as the underlying 
cause, every case of postmenopausal bleeding must undergo thorough evaluation. Many studies have been conducted all over the world till date, to evaluate different causes of postmenopausal bleeding.

All these studies whether prospective or retrospective, recruited postmenopausal patients, subjected them to Transvaginal sonography to measure endometrial thickness and then to endometrial sampling.

In the present study, 100 patients of postmenopausal bleeding subjected to TVS followed by fractional curettage and the comparison between endometrial thickness and endometrial histopathology done. The mean ET in cases of atrophic endometrium is $5.7 \mathrm{~mm}$ while the mean ET in cases of endometrial carcinoma is $11.95 \mathrm{~mm}$.

The Nordic multicentric study, which is the largest study till date, a prospective randomized controlled trial, recruited 1168 patients who were subjected to endometrial sampling by dilatation and curettage. Before curettage, Transvaginal sonography was done to measure endometrial thickness and then comparison between endometrial thickness and endometrial histopathology done. The results obtained were categorised into atrophic endometrium with mean ET 2.4-5.3 $\mathrm{mm}$, the corresponding figure for carcinoma was $9-32 \mathrm{~mm}$.

Bindman $\mathrm{S}$ et al completed a meta-analysis of 35 studies comparing the efficacy of TVS in diagnosing endometrial abnormalities in postmenopausal bleeding. 5298 patients were recruited out of which $13 \%$ had uterine cancer as the underlying pathology, $40 \%$ had endometrial polyp, while rest all were benign causes. In our study $9 \%$ patients had endometrial carcinoma while $12 \%$ had endometrial hyperplasia or polyp.

However, the present study differs from above studies as in the above studies; the main aim was whether the cut off limit of $4 \mathrm{~mm}$ on TVS was more suggestive of cancerous etiology. In the present study, 100 patients with postmenopausal bleeding were evaluated and comparison between ET and endometrial histopathology was done to know the distribution of different causes of postmenopausal bleeding, most common cause of PMB and $\%$ of endometrial cancer as the underlying cause. The results obtained were more or less similar to other studies.

Gredmark T et al conducted a study at health care County at Skoraborg, Sweden, over 18 months, including 457 women with postmenopausal bleeding and the frequency of bleeding correlated with the endometrial histopathology.

$50 \%$ atrophic endometrium, $10 \%$ endometrial hyperplasia, $9 \%$ polyp, $8 \%$ adenocarcinoma, $4 \%$ proliferative endometrium, $1 \%$ secretory endometrium, $14 \%$ unremarkable endometrium, $3 \%$ other causes.
Present study has much comparative results with the above study as follows; 54\% atrophic endometrium, 9\% adenocarcinoma, $12 \%$ normal and secretory endometrium, our study differs from the above study as in the above study Transvaginal sonography was not used to measure endometrial thickness prior to endometrial sampling and patients with postmenopausal bleeding were directly subjected to dilatation and curettage.

Ferazzi E et al conducted a prospected study over 18 centres including 930 patients having bleeding per vaginum at least 6 months after menopause. Endometrial thickness measured by Transvaginal sonography followed by histopathological evaluation. Endometrial carcinoma was found in $11.5 \%$ cases while $49.2 \%$ had atrophic endometrium. Cut off of $4 \mathrm{~mm}$ of ET on TVS had a sensitivity of $98 \%$ and negative predictive value of $99 \%$ to detect or exclude endometrial carcinoma respectively. In present study, the results obtained for underlying cause of postmenopausal bleeding are much similar but the sensitivity and predictive values of TVS can't be commented as only one patient had ET $<4 \mathrm{~mm}$.

Similarly in our study, only $8 \%$ patients had endometrial adenocarcinoma as the underlying cause of postmenopausal bleeding.

Conoscenti $G$ conducted a prospective study including 149 women with postmenopausal bleeding who then underwent TVS, hysteroscopy and dilatation and curettage.

Considering ET as a single parameter, it was concluded that cut off of $4 \mathrm{~mm}$ is the most sensitive for defining normality as only one case of carcinoma detected in patient with endometrial thickness $<4 \mathrm{~mm}$. In the present study, only one patient with postmenopausal bleeding had endometrial thickness $<4 \mathrm{~mm}$ on TVS, hence the sensitivity results could not be compared.

A study conducted at Rawalpindi hospitals including 167 postmenopausal patients with uterine bleeding were subjected to TVS and endometrial sampling and the results obtained showed that maximum no of patients were in $6^{\text {th }}$ decade where in the present study maximum no of patients were in $5^{\text {th }}$ and $6^{\text {th }}$ decade.

The mean age of menopause was 49 years while in present study it is around 47 years. The most common cause of postmenopausal bleeding in the above study was atrophic endometrium followed by proliferative endometrium and then endometrial hyperplasia and polyp. In our study also, the most common cause of postmenopausal bleeding was found to be endometrial atrophy followed by proliferative endometrium.

In the present study the results obtained were as follows; $79 \%$ benign histology, 25\% premalignant lesions, 9\% adenocarcinoma. 
It was also seen in the present study that multiparity has an association with carcinoma. This might be contrary to the statement that carcinoma endometrium is more common in nulliparous women due to more exposure to estrogen. The explanation that can be given is may be the age in which the patient presents with postmenopausal bleeding and carcinomatous histology is advanced and by that time, almost all women have had 3-4 confinements in Indian Territory.

Irshaid B et al conducted a retrospective study of hospital records of 482 women who represented with postmenopausal bleeding. Histopathology reports of these women reviewed and different causes of postmenopausal bleeding identified as; atrophic endometrium 52\%, hyperplasia $11 \%$, adenocarcinoma $9 \%$.

Results of the present study are much similar to this but the present study is prospective and includes TVS in the evaluation of patients with postmenopausal bleeding which was not used in above study.

Gupta et al conducted a prospective study at St. Antonius hospital, on 70 women who underwent operative hysteroscopy for evaluation of postmenopausal bleeding with endometrial thickness $>4 \mathrm{~mm}$ and the histological causes evaluated.

7 out of these $(10 \%)$ were diagnosed with carcinoma. The present study shows endometrial carcinoma as the underlying cause of postmenopausal bleeding in $9 \%$ patients. These results are almost similar.

Tandulwadkar S at Ruby Hall IVF and endoscopy centre conducted a prospective study on 60 women with postmenopausal bleeding who were subjected to TVS followed by hysteroscopy and biopsy and the histopathological results were analysed.
It was concluded that hysteroscopy is the accurate method for evaluation of endometrial pathology and it may provide treatment of benign lesions in the same sitting. In our study fractional curettage was done after diagnostic hysteroscopy to evaluate the endometrial pathology

Epstein E et al conducted a prospective study including 106 women with postmenopausal bleeding and endometrial thickness of $<5 \mathrm{~mm}$ on sonography who were subjected to endometrial sampling by dilatation and curettage.

Out of these $55 \%$ normal endometrium, $33 \%$ insufficient endometrial sampling, $8 \%$ polyp, $2 \%$ hyperplasia with atypia, $2 \%$ carcinoma.

Thus it was concluded that risk of carcinoma is much less in the patients with ET $<5 \mathrm{~mm}$ and it can be taken as cut off limit to decide whether further evaluation is mandatory.

In the above study only those patients with ET $<5 \mathrm{~mm}$ were subjected to $\mathrm{D}$ and $\mathrm{C}$ while in the present study all patients with postmenopausal bleeding were subjected to curettage.

Epstein E et al. also did related studies to compare hysteroscopy, saline sonosalpingography and D and C in evaluating endometrial lesions and found that hysteroscopy is superior to other 2 procedures in diagnosing endometrial pathology.

Study, comparison between ET and endometrial histopathology done rather than between two or more procedures used for endometrial evaluation.

Table 2: Comparative statistics of different studies.

\begin{tabular}{|c|c|c|c|c|c|}
\hline Study & $\begin{array}{l}\text { Nordic } \\
\text { Multricentric }\end{array}$ & $\begin{array}{l}\text { Smith } \\
\text { Bindman }\end{array}$ & $\begin{array}{l}\text { Thomas } \\
\text { Gredmark }\end{array}$ & E. Ferrari & Present study \\
\hline Most common age group & & & & & 45 to 54 years \\
\hline Age group in carcinoma PT & & & & & $>50$ years \\
\hline Mean age of menopause & & & & & 47 years \\
\hline Benign causes & & $47 \%$ & $72 \%$ & $49.2 \%$ & $79 \%$ \\
\hline Most common cause & & & $\begin{array}{l}\text { Atrophic } \\
\text { endometrium }\end{array}$ & $\begin{array}{l}\text { Atrophic } \\
\text { endometrium }\end{array}$ & $\begin{array}{l}\text { Atrophic } \\
\text { endometrium (54\%) }\end{array}$ \\
\hline Premalignant causes & & $40 \%$ & $19 \%$ & & $25 \%$ \\
\hline Malignancy & & $13 \%$ & $8 \%$ & $11.5 \%$ & $9 \%$ \\
\hline ET in atrophic endometrium & 2.4 to $5.3 \mathrm{~mm}$ & & & & $5.7 \mathrm{~mm}$ \\
\hline ET in carcinoma & 9.0 to $32 \mathrm{~mm}$ & & & & $11.95 \mathrm{~mm}$ \\
\hline
\end{tabular}


Table 3: Comparative statistics of different studies.

\begin{tabular}{|llllll|}
\hline Study & Rawalpindi & Bani Irshaid & Gupta & E. Epstein & Present study \\
\hline Most common age group & $6^{\text {th }}$ decade & & & 45 to 54 years \\
\hline $\begin{array}{l}\text { Age group in carcinoma } \\
\text { PTS }\end{array}$ & & & & $>50$ years \\
\hline Mean age of menopause & 49 years & & & 47 years \\
\hline Benign causes & $52 \%$ & & & $79 \%$ \\
\hline Most common cause & $\begin{array}{l}\text { Atrophic } \\
\text { endometrium }\end{array}$ & & & & $\begin{array}{l}\text { Atrophic } \\
\text { endometrium(54\%) }\end{array}$ \\
\hline Premalignant causes & $11 \%$ & & $10 \%$ & $25 \%$ \\
\hline Malignancy & $9 \%$ & $7 \%$ & $2 \%$ & $9 \%$ \\
\hline $\begin{array}{l}\text { ET in atrophic } \\
\text { endometrium }\end{array}$ & & & & $5.7 \mathrm{~mm}$ \\
\hline ET in carcinoma & & & & $11.95 \mathrm{~mm}$ \\
\hline
\end{tabular}

\section{CONCLUSION}

As per this study, we recommend that postmenopausal bleeding, should always be taken seriously, no matter how minimal or non-persistent it is, because though majority of causes underlying postmenopausal bleeding are benign, endometrial carcinoma may be seen in around $10 \%$ cases of postmenopausal bleeding and abnormal uterine bleeding is the first and most common symptom of carcinoma.

The apparent conclusion derived from the avalanche of literature in the genecology on the evaluation of postmenopausal bleeding, is that each case of postmenopausal bleeding must undergo thorough evaluation by endometrial sampling

Transvaginal ultrasound (TVUS) is considered an acceptable initial investigation in women with PMB. ${ }^{1,10}$ In this group of women an endometrial thickness of 4$5 \mathrm{~mm}$ typically correlates with low risk for endometrial disease As the endometrial thickness increases to $20 \mathrm{~mm}$ so too does the risk of endometrial cancer. ${ }^{10}$ It is important to remember that there is no accepted agreement on the cut-off for normal endometrial thickness and, thus, any women with risk factors and symptoms require endometrial sampling. ${ }^{3}$ There have been many studies looking at the sensitivity and specificity of TVUS in detecting endometrial cancer in women with $\mathrm{PMB}^{10}$. This varies depending on the endometrial thickness used. For example, a sensitivity and specificity of 96 and 53 per cent respectively for an endometrial thickness of $4 \mathrm{~mm}$ and 96 and 61 per cent respectively for endometrial thickness of $5 \mathrm{~mm} .{ }^{10}$

An endometrial biopsy is considered the gold standard for evaluation of PMB. ${ }^{8,10}$ Endometrial biopsy can be obtained with an endometrial pipelle in the outpatient setting, or by hysteroscopy and curettage (with or without dilatation) in either the outpatient or inpatient setting. ${ }^{10}$
Funding: No funding sources

Conflict of interest: None declared

Ethical approval: The study was approved by the Institutional Ethics Committee

\section{REFERENCES}

1. Goodman A. Postmenopausal uterine bleeding. UpToDate. Accessed online June 2014;16(3):54-5.

2. Parazzini F, La Vecchia C, Bocciolone L, Franceschi S. The epidemiology of endometrial cancer. Gynecol Oncol. 1991;41(1):1-16.

3. Jemal A, Siegel R, Ward E, Murray T, Xu J, Smigal Cet al. Cancer Statistics. CA Cancer J Clin. 2006; 56:106-30.

4. Lurain JR. Uterine Cancer In: Berek and Novak's Gynecology. 14th ed. Lippincott Williams and Wilkins, 2007;1344.

5. Lurain JR. Uterine Cancer In: Berek and Novak's Gynecology. 14th ed. Lippincott Williams and Wilkins, 2007;1348.

6. Gupta JK, Wilson S, Desai P, Hau C. How should we investigate women with postmenopausal bleeding? Acta Obstet Gynecol Scand. 1996;75:4759.

7. Gull B, Karrlsson B, Milsom I, Granberg D. Can ultrasound replace dilatation and curettage? A longitudinal evaluation of postmenopausal bleeding and Transvaginal sonographic measurement of endometrium as a predictor of endometrial cancer. Am J Obstet Gynecol. 2003;188:401-8.

8. Brand A. The women with postmenopausal bleeding. Australian Family Physician. 2007;36:116-20.

9. Smith-Bindman R, Weiss E, Feldstein V. How thick is too thick? When endometrial thickness should prompt biopsy in postmenopausal women without vaginal bleeding. Ultrasound Obstet Gynaecol. 2004;24:558-65.

10. Feldman S. Evaluation of the endometrium for malignant and premalignant disease. Up To Date. Accessed online June 20146. 
11. Lurain JR. Uterine Cancer In: Berek and Novak's Gynecology. 14th ed. Lippincott Williams and Wilkins. 2007;1346.

12. Bokhman JV. Two pathogenetic types of endometrial carcinoma. Gynecol Oncol. 1983;15:10-7.
Cite this article as: Chaudhari L, Satia MN. To study the correlation between endometrial thickness on transvaginal sonography and endometrial histopathology in women with postmenopausal bleeding. Int J Reprod Contracept Obstet Gynecol 2016;5:1309-15. 